$6^{\text {th }}$ Annual Organization Science Winter Conference, 9-13 February, 2000, Keystone, Colorado, US

\title{
ANALYSIS OF BUSINESS NETWORK DYNAMICS
}

\author{
Dr. Emanuela Todeva
}

\section{INTRODUCTION - NATURE AND BEHAVIOUR OF BUSINESS ACTORS}

This paper builds upon the advancements in structural analysis (Wellman and Berkowitz, eds. 1988), network analysis (Nohria \& Eccles, eds. 1992, Knoke and Guilarte, 1994), and a range of economic and management strategy theories, that have discussed the behaviour of interlinked economic agents.

Our definition for business networks is the following:

Business Networks are sets of repetitive transactions based on structural and relational formations with dynamic boundaries that comprise of interconnected elements (actors, resources and activities). Networks accommodate the contradictory aims pursued by each actor, and facilitate joint activities and repetitive exchanges that have specific directionality and flow of information, commodities, heterogeneous resources, individual affection, commitment and trust between the network members.

The literature on business networks usually refers to the companies as the main agents, interconnected into buyer-supplier chains. If we look at a supplier chain of a firm as a business network, we can see that while all partners are interested in completing the exchange (a common aim), all of them negotiate individual outcomes and try to maximise the benefits that this exchange brings to them (contradictory aims). Re-negotiation of benefits in a business network takes place almost at every transaction. The dynamics of connections between members depends usually on the activity of the core actors of the network, who dominate and control the negotiation process, and determine the 'membership status' of the peripheral members.

While there is no doubt that behind each firm stands a management team, composed by professionals in their own field, the literature still is dominated by the economic theories of firm behaviour. Conceptually it has been difficult to integrate the economic theories with the behavioural theories of the firm. While the former deals with issues of corporate governance, structure of costs, efficiency and productivity, the latter is focused on the actual process of decision making, and the individuals involved - with their multiple goals and authority relations in an organisational structure (Simon, 1957, Cyert and March, 1963). Firms are not only economic agents capable of strategic positioning in the market, but also social entities capable of learning and adaptive behaviour in dynamic and complex situations.

In general, the economic concepts usually address the similarities between network members and issues of 'typical' forms of behaviour. On the contrary, the managerial theories of the firm reveal motivational and structural characteristics of firms that generate individual and specific 
behaviour. We believe the two approaches are complementary in an interdisciplinary framework for network analysis. In this paper we look at some of the leading theories in both fields, and discuss the behavioural principles promoted by each of them. This, we believe, will enhance business network analysis with new concepts and perspectives.

It has been already admitted that the sociological theory after Weber has neglected the concept of the market and, therefore, it is not well-equipped to propose new conceptual framework for the analysis of firm's behaviour. However, the management and strategy literature provides alternative perspectives that could be contrasted with the economic theories, developed within the transaction cost framework.

Typically, the characteristics of network agents measured by network analysts are: centrality of one or more of the actors (in terms of their capacity to receive or send a disproportionate amount of relations with others), and direct vs. indirect contacts between the actors. The capacity of actors to connect to other actors through a number of steps demonstrates actors' dependency on information and resources, and is measured usually by the distance.

Subsequent concepts that derive from the measure of centrality are: the notion of an information broker (or actor with proportionately large number of incoming ties), and co-ordinator (an actor with proportionately large number of outgoing ties). It is important to mention that current theory does not generally discuss specific characteristics of the individual actors. The network members are assumed to have similar characteristics. However, it is self-evident that neither social networks, nor business networks comprise of equal members. The participation of individual member-firms in transactions and exchanges is specific, and is directly effected by the firm's size, by its history, by its product range and diversification, the market share, or by the market penetration through distribution channels - all company specific characteristics.

In this context, what is still an unexplored territory, is an assessment and comparison of the behaviour of different actors, including their motives, and their actions - what they actually do as being connected within a particular set of relations. The emphasis of our analysis is on firms' behaviour in a competitive market environment, determined by socially connected managers. This implies that the behaviour of firms is a result of managerial decisions and choices, affected by social and economic factors.

In the subsequent parts of the paper we examine various forms of behaviour of economic actors, connected in a value chain, or connected by market forces. All behavioural motives and actions are summarised in Fig. 1., where we present an abstract model of a heterogeneous business network.

\section{BEHAVIOUR IN BUSINESS NETWORKS}

The managerial theory of the firm launched with the work of Berle and Means (1932) on the issue of separation of ownership from control raises a number of issues. Among them are the questions of the motivational forces behind, and the control over a firm's behaviour. It rejects the assumption of profit-maximisation as a driving force in the market place, and introduces the assumption of managerial self-interest (Seth and Thomas, 1994). The firm's administrative 
apparatus, or firm's structure and hierarchy, become important factors, determining strategic decisions and economic transactions.

Penrose (1959) sees the firm as a collection of productive resources, and that each firm possesses a distinctive set of competencies, specialised resources, skills, tangible and intangible assets (including brand-name recognition, reputation, and market share). These are resources that provide firms with a competitive advantage in the market place.

However, firm's competencies, specialised resources, tangible and intangible assets could become advantages only if they are efficiently employed by the firm's managers. A large number of business cases demonstrate for example the importance of the abilities of company managers to lead a turnaround programme in order to position the firm better in continuously transforming market environment.

Overall the management theory of the firm equals the behaviour of the firm with the strategic behaviour of the managers, even though the later is a means of the former. The implications for network analysis are that both managers and firms could be placed in the nodes of a network. Relationship between two nodes - firms or managers - could take the form of exchange of both tangible and intangible assets and resources - products, services, information, practices, knowledge, or experience. In this respect, for the purpose of a network analysis both firms and managers represent economic agents involved in transactions. However, within the concept of 'business network' we envisage primarily relationships between firms that are formed through managerial decisions.

\section{- Accumulation of Heterogeneous Resources}

Considering the fact that all activities of economic actors involve one form or another of resource allocation, distribution, and utilisation, it is important to look at the way firms deal with the resource issue. The resource-based view of the firm sees companies as a bundle of heterogeneous resources. These resources are treated as an outcome of exogenous influences from the environment, rather than as a result of a proactive strategic behaviour, conducted in a dynamic environment - the latter being dominated by stochastic processes and various constraints and opportunities (Seth and Thomas, 1994). This economic view of the firm can explain a current level of resources, but can not address issues of changes in the level of resource.

Once we focus on the proactive behaviour of the firm, ruled by managerial utility and managerial self-interest (Mintzberg, 1983), the irrational component of the firm's decision making process becomes a dominant factor. The accumulation of heterogeneous resources becomes a selective and strategic process, and demonstrates the way management sees the future of the company. Managerial vision becomes a significant factor.

It is difficult to establish the causality between accumulated resources and assets, and specific strategic decisions. Both are simultaneously constraints and opportunities for each other. Managers make decisions which they see as appropriate to the current access to resources. On 
the other hand, managers proactively seek and accumulate resources in order to extend the scope for their business decisions.

Each member of a business network is capable of accumulation of resources, or what we would call, network capital ${ }^{1}$ - heterogeneous resources, committed by each actor, and designated for business activities and transactions within the business network. The accumulation of network capital is driven by the primary objective of each firm to re-locate and re-position itself in the network, which will extend its ability to exercise more control over future contracts and transactions with buyers and suppliers.

Managerial strategies related to resource accumulation will have a significant impact on the level of cohesion and competition within the network, on the structure and configuration of relationships, and on the reciprocity of exchanges between members. The exogenous influences on firm's behaviour will come from the set of ties, which the firm has established along the value chain of suppliers and buyers, and also from the broader business environment of competitors, regulators, and related markets.

Inspite of its limitations, the resource-based theory of the firm explains the inequality between network members in terms of accumulated resources, and the directionality of their efforts to maintain and establish new ties in order to increase the resource level.

\section{- Minimising Costs and Maximising Benefits}

The inequality between network members derives also from their different capabilities to manage their costs. This line of argument is particularly well developed within the transaction cost theory (Coase, 1937, Williamson, 1975, 1981, 1985). The cost structure of the economic agents is affected by their assets specificity, by the uncertainty, and the frequency of transactions. Their behaviour therefore, aimed at the reduction of transaction costs, is expected to include efforts to increase the more general use of their assets, to control the uncertainty of their market transactions, and to increase the frequency (or volume) of transactions.

Minimisation of costs, therefore, is based on specific business activities, such as: diversifying assets and capabilities, securing long-term contracts, and making commitments to buyers and suppliers. These activities include among others the development of hierarchical relations within and between the interconnected economic actors.

\footnotetext{
${ }^{1}$ The term 'capital' is used by Burt (1992) who refers to three types of capital - financial capital (cash, bank reserves, or lines of credit), human capital (abilities, experience, formal education and training), and social capital (contacts and relations). We introduce the term network capital as a concept that builds upon the relational content of social capital, and includes the resources, engaged in network links. A business network is constructed not only by links and relationships between economic agents, but also by contracts and agreements between them, that tiedup specific resources, committed by each member, and therefore develop dependencies and liabilities between the contracting parties.
} 


\section{- Maximising Payoffs}

In addition to the motives for accumulation of resources and minimisation of costs, economic agents are driven by motives for maximisation of benefits, compared with other known to them actors. Another theory, which aims to analyse the underlying motives of strategic behaviour in a competitive environment under the conditions of limited access to information and resources, is the non-co-operative game theory. According to the leading theorists in this field, the players aim at maximising their payoffs in a wider sense, rather than maximising profits. Their market strategy, is determined by the market structure. The players continuously create for themselves more favourable market position, from which they have increased chances of 'outdoing their adversaries', knowing that the adversaries are trying to do the same (Encaoua et al., 1986, Dixit and Nalebuff, 1991, Seth and Thomas, 1994).

The decisions that firms make in this game scenario depend on the available information and resources. Examples of non-co-operative strategies by economic agents, according to Shapiro's survey, are a number of strategic actions in already concentrated industries. These typically include: investment in physical capital, investment in intangible assets, strategic control of information, and horizontal mergers (Shapiro, 1989).

Concentrated industries usually are characterised by few players, engaged in direct competition. In this context, firms are motivated to extend their capacity through investment in physical assets; to move forward their competitive edge through investment in intangible assets; to maintain their leading position by strategic control of information; and to reduce competition through horizontal mergers. All these manoeuvres are perceived by firms as re-positioning and maximising the payoffs from the current position.

Non-co-operative game theory describes well the process of repositioning in a competitive environment. It highlights how temporary is any description of the economic agents as engaged in relationships within their network of buyers and suppliers. This analysis also calls for a change of the traditional view of business networks as ego-centred sets of firms, connected to their buyers and suppliers. The behaviour of network members is very much affected by the activities of their competitors. It may also include connecting to competitors through mergers, acquisitions, and co-operative alliances. We discuss further in the paper more details of cooperative strategies, applied by inter-connected actors.

In the context of industrial analysis and network analysis we also could draw a parallel between behaviour of firms in 'concentrated industries' and in networks with high density. Expected behaviour by the network members will be one of personal investment in new links and contract relations, with attempts to build asymmetries through control of information, or through intranetwork re-groupings.

In their competition for more favourable position in the network, actors tend to increase asymmetries in their relations, and to create inequalities that may lead to potential confrontational links. This suggests a new research agenda for network analysis focused on the confrontational potential of any form of alliance between interrelated network members. 


\section{- Bargaining and Negotiating Contracts}

We would like to stress that the non-co-operative game theory projects motives and behaviour of actors entirely dis-engaged from contracts and relationships with others. The agency theory of the firm on the contrary, looks at the company as governed by a set of contractual relations. The firm is only a single actor, or an agent engaged in bi-lateral and multi-lateral contracts. The bargaining and the political nature of these contracts is assumed. Their content is influenced by the external environment, and by the inter-firm relations with other individuals or organisations. So, the behaviour of the firm in the market place depends on its contractual relations with other economic actors, which are continuously re-negotiated.

The agency theory highlights that network ties are not fixed, but are dynamic. It also reveals the political nature of network members, involved in continuous negotiations of contracts. This influences our perception of the nature of network ties between different firms, as being one of balanced competition and co-operation. The balance is determined by the existing contracts between economic agents, and by the abilities of some members to change contracts unilaterally ${ }^{2}$.

The implications for network analysis are that more attention needs to be paid to: the structural and relational asymmetries (like direct vs. indirect contacts); to the number and the type of incoming vs. outgoing relations; to the reciprocity in existing relations; the centrality and betweenness of contacts; and the capacity to produce dependencies within the network through non-redundant ties. Relational asymmetries are particularly evident in contracts where exchange of resources and payments is fixed, allowing each firm to calculate individually the added value from a contract.

\section{- Co-operating for a Final Outcome}

The co-operation between the contracting parties in a market environment is assumed by most of the economic theories in order for a transaction to take place. The stakeholders' theory assumes also co-operation within a network of agents with vested interests in the final outcome. The interests of these agents include an intent to extend the co-operative action. However, their interests are also contradictory (like for example the tensions between buyers and sellers, managers and shareholders). Each stakeholder's group aims at maximising its benefits, even if it is at the disadvantage of the others. In this respect, the difference between the non-co-operative game theory and the stakeholders' theory is that the latter assumes higher co-operation in a competitive environment.

The dynamics of the relationships between different stakeholders highlight further the need for more attention to network processes rather than structure. The research on actors' interests leads to a focus on the dynamics of ties and relations, rather than their structural configuration. Appropriate methodologies for relational analysis are usually based on qualitative data. The

\footnotetext{
${ }^{2}$ All networks are characterised by certain asymmetries when some members in some positions, particularly those with high number of non-redundant contacts (Burt, 1992), are able to control the network processes. Dominant stakeholders may decide to honour contracts, or as all examples of market failures show, they could change terms of contracts unilaterally and without negotiations.
} 
work by Chwe (1996) on communication and co-ordination in social networks is a serious attempt to quantify individual strategies through measurement of individual 'thresholds' of reaction.

According to Chwe, each individual member has a specific 'threshold' of reaction to an event, or to other members' behaviour. This threshold evolves over time. It is highly dependent on the individual preferences and on the knowledge of the preferences of the 'other' participants. If one has limited knowledge of the preferences of the others, it is difficult to choose a mode of action and to estimate appropriateness. The assumption is that when motives and stimulus are below the threshold, and the preferences are high and no positive outcomes are expected, agents don't act. The behaviour of network members is therefore an outcome of the choices of individual agents to act accordingly to their preferred outcomes, and the preferences of the 'others'.

The stakeholders' theory advocates that network members have a mutual interest to participate in the network activities. However, it does not suggest by any means that all agents are equally positioned, and that they have complementary interests. On the contrary, the complementarity comes through communication and co-ordination of the joint activities, and the increased awareness of the preferences of the 'other' stakeholders. We may conclude that the stakeholders theory does not advocate that network members have a co-operative nature, but through their joint activities they are capable to communicate their interests and preferences, and to coordinate co-operative actions.

\section{- Forming Coalitions}

Insights on managerial choices could be found in the work on power in organisations by Mintzberg (1983) and Pfeffer (1992), and the work on interlocking corporate directorates by Scott and Burt (Burt, 1979, Scott, 1987). Mintzberg's definition of power as 'the capacity to effect (or affect) organisational outcomes' (Mintzberg, 1983, p. 4) suggests a number of implications.

One of them is that the effectiveness of a group effort will be different from the effectiveness of an individual effort, and therefore will have different impact on the organisational outcomes. So, the 'capacity' (i.e. the power) will differ by the strength and the direction of one's effort in relation to the efforts of the other actors in an organisation. An example will be a conflict situation between two actors within the same organisation, who have different objectives or contradictory views of how to act in pursuing an aim already agreed upon. If there is a disagreement between these actors, the directions of their efforts will differ, and therefore a substantial amount of energy will be wasted by both of them to neutralise the effect from the rival action of the other.

This is a good example why managers form coalitions in order to achieve certain objectives in certain ways. These coalitions usually aim to ensure that all participants share similar objectives and similar views on how to achieve these objectives. A collective strategy will obviously improve the efficiency of an action in organisational settings. Forming a coalition in network 
analysis is known as formation of cliques (or 'action sets' - Knoke, 1994), and is seen as having a negative impact on the equality of distribution of information and resources.

In reference to network analysis, the example above of a conflict situation shows a network with low cohesion or high competition between two different actors. We may expect that in low cohesion networks actors would have conflicting strategies and interests, and formal contract and relations between them would be unstable. Actors will seek to secure the desirable outcomes through building wider coalitions.

We have to stress that network members engaged in a coalition, or an action set, do not act necessarily in a coherent way. There might be a discrepancy between the desirable outcomes, perceived by each actor, or the extent to which goals and strategies are shared.

If the network members have conflicting objectives and intentions, they will interpret the link in a different way, seeing different opportunities for themselves, and creating asymmetries within the action set in order to achieve their own objectives. Whether they are able to do so will depend on their position within the network structure and their capacity to generate support for their plans through coalitions. A major question is what factors increase cohesion in a network, and how trust, loyalty, and commitment relate to the diversity of goals of the members.

\section{- Preferences, Decision Making, and Goal Setting}

Mintzberg's discussion on preferences and goal setting is quite adversarial, and suggests that members of an organisation (assumed as an intra-organisational network of individuals) are involved in a complex process of negotiation over organisational objectives. As an introduction to his theory of power in organisations, Mintzberg refers to the work by Cyert and March (1963) on coalitions to discuss the fact that the establishment of organisation's goals is far from a rational process. All outside and inside participants in the decision making process are continuously bargaining and negotiating with each other the inducements in return for contributions. Therefore the determination of the outcomes (or the organisational goals) is a result of the dynamics of 'shifting participants, shifting needs, shifting power within the coalition’ (Mintzberg, 1983, p. 16).

To establish further the intra-organisational dynamics, Mintzberg (1983) refers also to the work by Petro Georgiou (1973), that looks at the concept of the organisation as an arbitrary defined focus of interests. Georgiou views the internal and the external participants in organisational goal setting as a strategic force in the organisation, whose behaviour is determined by the rewards they pursue. The process of decision making and goal setting is also seen as a market exchange of incentives. In this view the market is seen as a fundamental process, which is part of the functioning of the organisational hierarchy.

This analysis translated into the network discourse means that in a network there is an ongoing process of re-distribution of resources and information which aims to shift the balance of power and influence. This adversarial tendency between network members could be outwit in two ways: either by enhancing control and dependency (and creating hierarchy of subordination in a network), or by developing trust and commitment to the existing contracts and relations. This 
suggests that there are two main types of networks - self-regulating (through norms, rules, loyalty, commitment and trust) and regulated (either internally by powerful members, or externally through hierarchies).

It is important to mention that the two types are ideal and form a scale that may accommodate all practical cases of business networks. In regulated networks there are rules and norms that govern the contract relations, while the goal-setting could still be spontaneous process, lead by the network entrepreneours.

\section{- Self-co-ordination vs. Co-ordination Agency}

Business and management networks exist in a broader environment, which usually provides a set of rules, and regulations that affect the network performance and operations. Some networks in their evolution achieve high level of cohesion based on trust and commitment by all members to prolong the existing relations. However, we may expect that the majority of networks envisage a certain level of asymmetry which is generated by larger firms, by more experienced managers, or by charismatic leaders. These network leaders are expected to have a major impact on the structure of the entire net, on the rules and regulations for performance, and on the specific distribution of inducements, incentives and profits.

Mintzberg (1983) refers back to a 1952 paper by Papandreou about the existence of multiple objectives coming from the internal and the external environment, passing through a peak coordinator that reconciles these goals into a single preference function. The concept of a peak coordinator could be liased with the concept of a co-ordinating agency in a network, or actors with high concentration of non-redundant contacts who occupy positions of high centrality, and are located close to structural holes (Burt, 1992, Brass, 1992). The difficulty with a network analysis is to identify these co-ordinating agents that set communication and decision priorities for the entire net.

Usually it is assumed that networks imply a mechanism of self-co-ordination and selforganisation among de-centralised parts (or agents), in a process of information exchange. However, network analysis has not found yet significant evidence for self-co-ordination as a widely implied mechanism in the real business world, but rather as an exception. On the contrary, the dynamics of relations between different agents suggest that business network structures transform into hierarchies under certain conditions (i.e. in joint ventures, acquisitions, horizontal and vertical integrations), or represent equally competitive environments, such as markets (i.e. in the case of subcontracting, outsourcing, and alternative suppliers).

\section{- Entrepreneurship - Initiation of New Transactions and Contacts}

Leading actors in this process are those that initiate transactions and new relationships, called by Burt 'network entrepreneurs'. They are the first to identify a new business opportunity, and to pursue the realisation of that opportunity through establishing new relationships (see Burt, 1992). This means that usually some members of the network have at least the time advantage in negotiating formal contracts that substantiate a relationship between partners. 
Entrepreneurs who establish links with other agents for exchange of goods and services, information and ideas, affects, or influence (Tichy, Tushman, and Fombrun, 1979, p. 508) usually build wide networks. It is expected that these entrepreneurs will have high level of centrality in the network, and will have initially high level of control over decisions in that network. The evolution of the network will depend to a great extent on the vision of these 'network designers' and their ability to lead the network processes. The network processes include the exchange of incentives between actors through setting objectives with desirable outcomes, and through exchange of rewards.

\section{- Acquiring and Maintaining Power in Business Networks}

Another perspective on the structure of business networks comes from the strategy literature, and particularly the work by Porter on value chains. Porter's framework deals with the issues of assets creation, or relocation and concentration of resources within the value chain of a company and the wider value system ${ }^{3}$. According to Porter, organisational power is measured through the 'sustainability of profits against bargaining (by suppliers and buyers), and against direct and indirect competition' (by existing competitors, new entrants and substitutes of products and services) (Porter, 1991, p. 100).

The sustainability of profits by businesses is achieved through a range of strategic activities within the firm's value chain and within the overall value system. A firm gains power and strengthens its position in the value system by creating assets external to it, which could be tangible (such as contracts) and intangible (such as brand images, relationships with customers and network ties) (Porter, 1991).

However, Porter makes it perfectly clear that firm's advancement to a favourable position is achieved through the initial conditions (including pre-existing reputation, skills, routine practices), through the managerial choices of which activities to perform, and through the supporting investments in assets and skills (or allocation of resources within the value chain). Here, the value chain is part of the value system that is understood as the network of suppliers and buyers, maintained by each company.

From this perspective, it is important to note that firms as members of a network are continuously involved in value creation in order to maintain their position on the market (i.e. in the value system), or to advance their position. Advancement will mean higher bargaining power against suppliers and buyers, and more stable position against competitors. The very notion of the market suggests a certain level of competition, and therefore an orientation of all firms in the business network to pursue individual interests. On the contrary, an attempt for pursuing collective interests and objectives will be regarded as an attempt to avoid market pressures and uncertainty.

\footnotetext{
${ }^{3}$ According to Porter (1985) the 'value system' comprises of: a) upstream value chain of suppliers; b) the firm’s value chain; c) downstream value chains of distribution channels and end-users. The 'value chain' of the firm itself comprises of the firm's infrastructure, human resource management, technology development, procurement, inbound logistics, operations, outbound logistics, marketing, sales, and services.
} 
Managerial choices in this respect will depend not only on how managers perceive the interest of their company, but also how they perceive their partners in the value chain. Long-term commitment to a partnership is something that has to be nurtured through mutual understanding, and to be enhanced through personal relationships.

\section{- Control and Manipulation of the External and the Internal Environment}

A corresponding framework in organisation and management theory is Robbins's (1990) environmental management, which includes internal and external strategies applied by firms and managers. The internal strategies, according to the author, are environmental scanning (to analyse the position of stakeholders, government, competitors, trade unions), domain choice (or targeting a specific market niche), recruitment (or personnel selection and accumulation of human capital), geographic dispersion (targeting geographically disconnected markets to tackle political risk), buffering (flexibility in contracts to ensure alternative suppliers and absorption of outputs), smoothing (levelling out fluctuations in the market), rationing (re-location of resources according to priorities and situations) (Robbins, 1990).

The external strategies include: advertising (to manipulate the demand and the price sensitivity of customers), coopting (to absorb individuals that otherwise may threaten the firm's operations e.g. through interlocking directorates), lobbying (to influence regulatory bodies in order to achieve favourable outcomes from government policy and legislation), sub-contracting (to externalise costs and to protect changes in quantity and price), coalescing (to form mergers and joint ventures for lessening inter-organisational competition and dependency) (Robbins, 1990, pp. 358-375).

All internal and external strategies by their nature represent behaviour oriented towards the alteration or the maintenance of a particular network position and specific network relationships in which the firm is involved. The 'environmental scanning' in practice is gathering information about the network. 'Domain choice' is behaviour oriented towards preferential location in the production network and the market segment. 'Recruitment' and 'geographic dispersion' are forms of behaviour that enhance firm's capacity to control its performance and network ties. It is also an investment in intangible assets in order to gain a comparative advantage in relation to other firms. 'Buffering', 'smoothing' and 'rationing' are all directed towards absorbing and modulating pressures on the entrance and the exit of the firm in order to protect existing business relations.

The external strategies are also oriented towards repositioning in the market place and enhancing certain relationships with customers (through 'advertising'), with shareholders, banks, governments or competitors (through 'coopting' and 'lobbying'), and with partner businesses (through 'sub-contracting' and coalescing').

All these examples of environmental management strategies highlight the fact that network members are not indifferent in relation to the network configuration, but are active participants that are able to transform and manipulate network ties. 
The review of the economic and management theories of the firm suggests that the research agenda on networks could be enlarged beyond the structuralist approach. The behaviour of the network members is equally important as the structure of relations, and requires an equal attention by network analysts.

\section{- Mimicry and Normative Compliance in Business Networks}

The managerial practices of manipulating their external and internal environment mentioned above, are common for many businesses. This is supported also by the institutionalisation theory, which puts emphasis on the coercive, mimetic, or normative isomorphism among business organisations (Di Magio and Powel, 1983). However, the management and strategy theories extend the notion of organisational changes, as due mainly to environmental pressures, and introduce an alternative view of the firm.

On one side, environmental management practices show abilities of the organisations to affect their environment in a strategic manner, rather than responding to it. On the other side, institutionalisation theory emphasises the reactive behaviour of business organisations in compliance with normative pressures from the state, or mimicry towards established benchmarks by industry leaders. This demonstrates that there are theoretical grounds to expect both compliant and manipulative behaviour in business networks. The choice will reside with the managers of the firm, following their subjective evaluation of individual business situations.

Fig 2. visualises some of the key types of strategic behaviour within a business network, that derive from our discussion of the strategy and management literature. These are: bargaining and negotiation between linked actors, repositioning of the members, maximising profits and payoffs, minimising costs, investment in assets, capabilities and new relations, building strategic capabilities, accumulation of heterogeneous resources, manipulation of the external and the internal environment (including, for example, market demand, cost-effectiveness, product quality, etc.), decision making and goal setting, mimicry and compliance, co-operation, coordination, forming coalitions, entrepreneurship, initiation of contracts, acquiring and maintaining power..

This abstract model represents also a variety of relationships between network members: for example ,competition between A and A2 for contracts with C; different relationships with the environment maintained by $A$ and $C$ (where $C$ has an incoming link, while $A$ has both incoming and outgoing ties); different types of centrality between B and C (based of incoming vs. outgoing relationships); different incoming ties which $B$ receives from $C$ and $D$ (symbolising variations in quantity of exchanges resources); different directionality of links between B-C and B-A. Particularly interesting is the relationship between $C$ and $D$, which symbolises a multidimensional link that includes a long-term open-ended contract for joint activities, mutual payment links, and two directional exchanges of resources. The boundaries of this abstract business network are loose as it involves the potential of continuous changes of buyers and suppliers, incorporating new members and terminating contracts and exchanges with old ones. 
Fig. 1.: Network Dynamics

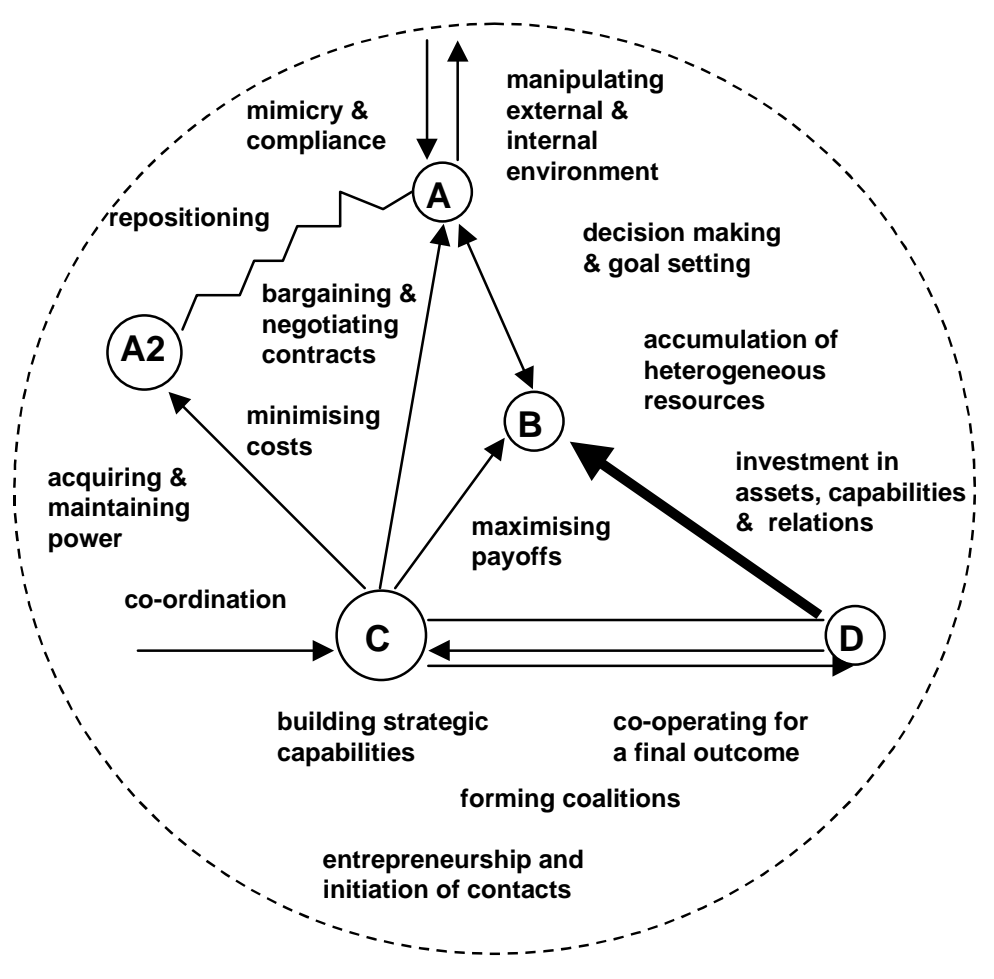

\section{THE CONTENT OF RELATIONSHIPS IN BUSINESS NETWORKS}

One of the fundamental barriers to network analysis is the duality of the nature of business networks - being simultaneously social and economic structures as well as dynamic processes of transactions between firms. The structuralist paradigm attempts to define basic assumptions that explain how network members are linked together and how these ties facilitate exchange of resources of any kind. However, this analysis is of limited value to practising managers who need not only to construct relations in the real business world, but also to fill these relations with content. Pro-active behaviour in a business network requires understanding of the behaviour of the other network members, their motives and preferences.

Analysis of the content of network relations requires much more holistic approach (Buckley and Chapman, 1996). As discussed in this paper, the content of a relation is determined by the two partners involved in it. Both actors usually define their individual preferences and exchange information about their intentions. The contract between them evolves as a negotiated strategy for mutual co-operation. The content of the relation therefore includes: a) the individual intentions of the partners, b) the negotiated strategy between them, and c) the exchange of information and resources, or the transaction itself. This complexity requires also more in-depth analysis of the entire set of relations of each partner, rather than merely mapping existing structural links. 


\section{CONCLUSIONS}

The existing research on networks puts emphasis on three aspects - the 'nodes', identified as the actors, the structure of ties, and the relations themselves measured mainly through directionality and reciprocity.

One of the advancements made by the structural analysis is to recognise the embeddedness of market transactions in the structure of social relations. However, the practical consequences of that fact remain hidden in implicit assumptions about network ties, relations and attitudes of the actors. The recognition of power and dependency in social networks has driven structural analysts to study the effect of different structural configurations. The fact that relations between network members generate specific network dynamics has been largely ignored. It is this dynamics that is of primary interest in some managerial theories that deal with issues of actor's choices and strategies. These are the conceptual frameworks of Mintzberg (1983) on intra- and inter-organisational power relations, and Porter's theory of competitive advantage built by organisations through extending their control over the value chain and the value system (Porter, 1991).

The economic theories discussed in this paper, aim to analyse company behaviour, and are a valuable source for new research concepts and frameworks that could be used in network analysis. The resource-based view of the firm gives another perspective on the process of accumulation and distribution of resources. Issues of network cohesion are in direct contradiction with the practice of unequal concentration of resources within the net. Reciprocity of exchanges could exist only between equally resourced partners. Managerial strategies to accumulate resources vital for their firms will continuously increase inequality in a network, unless all managers adopt a completely new principle of partnership simultaneously.

The non-co-operative game theory enhances the view of the adversarial nature of network members. Co-operation vs. confrontation requires not only negotiations at the level of individual strategies, but much higher level of co-ordination - either based on moral principles of trust, loyalty and commitment, or facilitated by a co-ordinating agency (internal or external to the network).

The agency theory brings more insights into the formal and informal contracts that facilitate exchanges between partners in a network. The stakeholders' theory takes a step further towards recognition of mutual interests beyond contradictory objectives. However, the emphasis is still on the decision making process that takes place in a network and the subordination of decisions, according to shared goals and individual interests.

The managerial theory of the firm puts emphasis on the variety of competencies, specialised resources and assets that each firm has in principle, and the tendency of the firm to develop further a unique character in order to acquire a strategic advantage. All these factors will serve to increase inequality in a network, which will raise the opportunity for development of coordination centres. This fact diminishes all discourse of the co-operative nature of network relations and the implied self-co-ordinating mechanism. 
The principle of self-co-ordination is also undermined by a series of research in the strategy and management field, such as: the concentration and distribution of power within a network (in the context of the work by Mintzberg (1983), Scott (1987), Pfeffer (1992), and Burt (1992); the issue of directionality of efforts and shared objectives by network members (Burt, 1979, Mintzberg, 1983, Scott, 1987); the notion of a 'peak co-ordinator in a network (Papandreou, 1952, Mintzberg, 1983); the negotiations of rewards in return for contributions between network members (Cyert and March, 1963); the exchange of incentives along with exchange of resources (Georgiou, 1973); strategic repositioning in a network through asset creation and an increase of the bargaining power of the actor, and through establishment of horizontal and vertical 'partnerships' across the value chain (Porter, 1991).

A detailed analysis of the individual characteristics of the network members would contribute significantly to an explanation of the specific distribution and concentration of resources. There is also very little work done on the self-co-ordination and self-regulation mechanisms within network structures. In terms of intra-organisational dynamics, a synthesis is required between principles that derive from social psychology and organisational behaviour theory, and from the economic theory.

Further research into the domain of relational dynamics in a network will not only enhance the value of previous research, but will allow more practical use of the findings. More practical research also will imply different set of research questions. For example: What types of strategic networks exist at national and international level? How large firms and holding companies transform their dependencies within the value-chain into advantages (like i.e. economies of scale)? How new business networks get established and what is the effect of new weak ties on the performance and restructuring of a network? What is the balance between high flexibility in contracts and more stable co-operative alignments in terms of effective network dynamics? Why some firms are not able to transform their network relations and to develop new business linkages? What is the effect of inter- and intra-industry processes on company networks? How membership in professional and political networks by managers or other stakeholders affects company performance? How risk and uncertainty of the business environment affect network cohesion and structure?

Within the same accord of practical application of network theory Lester (1992) suggests that the future of management lies in a dynamic information exchange, in decentralised decision making, in boundaryles organisations with emphasis on self-organisation of work, and personal relationships. This description resembles the concept of a network as an alternative form of organisation of economic activities.

Finally, we would like to stress that network theory is very far from consolidation. However, it offers a unique opportunity for an interdisciplinary endeavour to integrate knowledge from different social sciences, and to extend our understanding of the behaviour of interlinked firms as economic and social entities. 


\section{BIBLIOGRAPHY}

Arino, A. (1997) "Veracity and Commitment: Co-operative Behaviour in Firs Time Collaborative Ventures", In: Co-operative Strategies: European Perspective, Ed. by Beamish, P. and Killing, J., The New Lexington Press, San Francisco.

Bearden, J. and Mintz, B. (1987) "The Structure of Class Cohesion: The Corporate Network and Its Dual”, In: Intercorporate Relations: The Structural Analysis of Business, Mizruchi, M., \& Schwartz, M. (Eds.), Cambridge University Press, N.Y., pp. 187-207.

Berkowitz, S., (1988) "Markets and Market-Areas: Some Preliminary Formulations”, In: Social Structures: A Network Approach, Ed. by Wellman, B. and Berkowitz, S., Cambridge, Mass: Cambridge University Press.

Biggart, N. and Hamilton, G. (1992) "On The Limits of a Firm-Based Theory to Explain Business Networks: The Western Bias of Neo-classical Economics”, In: Networks and Organisations: Structure, Form, and Action, Ed. by Nohria, N. and Eccles, R., Harvard Business School Press, Boston, Massachusetts.

Brass, D. (1992) "Power in Organisations: A Social Network Perspective”, In: Research in Politics and Society, Vol. 4, pp. 259-323, JAI Press Inc.

Brass, D. and Burkhardt, M. (1992) "Centrality and Power in Organisations”, In: Networks and Organisations: Structure, Form, and Action, Ed. by Nohria, N. and Eccles, R., Harvard Business School Press, Boston, Massachusetts.

Buckley, P. and Chapman, M. (1996) "Economics and Social Anthropology - Reconciling Differences”, In: Human Relations, Vol. 49, No. 9, pp. 1123-1150.

Burt, R. (1979) "A Structural Theory of Interlocking Corporate Directorates”, In: Social Networks, Vol. 1, pp. 415-435.

Burt, R. (1992) “The Social Structure of Competition”, In: Networks and Organisations: Structure, Form, and Action, Ed. by Nohria, N. and Eccles, R., Harvard Business School Press, Boston, Massachusetts.

Casson, M. (1997) “An Economic Model of International Joint Venture Strategy”, In: Cooperative Strategies: European Perspective, Ed. by Beamish, P. and Killing, J., The New Lexington Press, San Francisco.

Chwe, M. (1996) Structure and Strategy in Collective Action: Communication and Coordination in Social Networks, [http://www.spc.uchicago.edu/ wwwchwe].

Coase, Ronald (1937) "The Nature of the Firm”. Economica. Vol. 4: 386-405.

Cyert, R., and March, J. (1963) A Behavioural Theory of the Firm. Prentice-Hall, Englewood Cliffs, N. J.

DiMaggio, Paul and Powell, W. (1983) "The Iron Cage Revisited: Institutional Isomorphism and Collective Rationality in Organisational Fields.” American Sociological Review, Vol. 48 (April): 147-160.

Dixit, A. and Nalebuff, B. (1991) Thinking Strategically. Norton, New York.

Encaoua, D. et al., (1986) "Strategic Competition and the Persistence of Dominant Firms: A Survey”, In: New Developments in The Analysis of Market Structure, Stiglitz, J. and Mathewson, F. (eds.), Macmillan, London.

Erickson, B. (1988) “The Relational Basis of Attitudes”, In: Social Structures: A Network Approach, Ed. by Wellman, B. and Berkowitz, S., Cambridge, Mass: Cambridge University Press. 
Garrahan, P. and Stewart, P. (1992) The Nissan Enigma: Flexibility as Work in a Local Economy. Mansell Publ., London.

Georgiou, P. (1973) “The Goal Paradigm and Notes Towards a Counter Paradigm”, Administrative Science Quarterly, 1973, pp. 291-310

Gerlach, M. (1992) Alliance Capitalism: The Social Organisation of Japanese Business, University of California Press, Berkeley.

Gerlach, M. and Lincoln, J. (1992) "The Organisation of Business Networks in the United States and Japan”, In: Networks and Organisations: Structure, Form, and Action, Ed. by Nohria, N. and Eccles, R., Harvard Business School Press, Boston, Massachusetts.

Grabher and Stark (1997) Restructuring Networks in Post-Socialism: Legacies, Linkages, and Localities. Oxford University Press, London.

Griffin, T. (1993) International Marketing Communications. Butterworth-Heinemann, Oxford.

Harrigan, K. (1995) "The Role of Inter-company Co-operation in Integrated Strategy: Strategic Alliances and Partnering Arrangements”, In: Advances in Strategic Management, Vol. 11, Part B, JAI Press Inc., Greenwich, Connecticut.

Holm, D. et.al, (1997) "Business Networks and Co-operation in International Business Relations”, In: Co-operative Strategies: European Perspective, Ed. by Beamish, P. and Killing, J., The New Lexington Press, San Francisco.

Ibarra, H. (1992) "Structural Alignments, Individual Strategies, and Managerial Action: Elements Toward a Network Theory of Getting Things Done”, In: Networks and Organisations: Structure, Form, and Action, Ed. by Nohria, N. and Eccles, R., Harvard Business School Press, Boston, Massachusetts.

Knoke, D. and Kuklinski, J. (1982) Network Analysis. Beverly Hills: Sage Publ.

Knoke, D. and Guilarte, M. (1994) "Networks in Organisational Structures and Strategies”, In: Current Perspectives in Social Theory, Supplement 1, pp. 77-115, JAI Press Inc.

Krackhardt, D. (1992) "The Strength of Strong Ties: The Importance of Philos in Organisations”, In: Networks and Organisations: Structure, Form, and Action, Ed. by Nohria, N. and Eccles, R., Harvard Business School Press, Boston, Massachusetts.

Lester, T. (1992) “The Rise of the Network”, In: International Management, June 1992, Vol. 47, NO. 6, pp. 72-73.

Lorriman, J. and Kenjo, T. (1994) Japan's Winning Margins. Oxford University Press, Oxford.

Mintzberg, H. (1983) Power In and Around Organisations. Prentice-Hall, Englewood Cliffs, N.

Nohria, N. \& Eccles, R. (Eds.) (1992) Networks and Organisations. Structure, Form, and Action. Harvard Business School Press, Boston, Massachusetts.

Ouchi, W. (1991) “Markets, Bureaucracies and Clans”, In: Markets, Hierarchies \& Networks: The Co-ordination of Social Life, Ed. by Thompson, G. et.al. al, Sage Publ., London.

Papandreou, A. (1952) "Some Basic Problems in the Theory of the Firm”, In: A Survey of Contemporary Economics, Vol. 2, ed. B. Haley. Irwin, Homewood, Ill.

Penrose, E. (1959) The Theory of the Growth of the Firm. Sharpe, New York.

Pisello, T. (1996) “Cost-Proofing: The Enterprise Network”, In: Data Communications, May 21, 1996, pp. 79-83.

Pfeffer, J. (1987) “A Resource Dependence Perspective on Intercorporate Relations”, In: Intercorporate Relations: The Structural Analysis of Business, Mizruchi, M., \& Schwartz, M. (Eds.), Cambridge University Press, N.Y., pp. 25-55.

Pfeffer, J. (1992) Managing with Power: Politics and Influence in Organisations. Harvard Business School Press, Boston, Mass. 
Porter, M. (1985) Competitive Advantage: creating and Sustaining Superior Performance, The Free Press.

Porter, M. (1991) “Towards a Dynamic Theory of Strategy”, In: Strategic Management Journal, Vol. 12, pp. 95-117.

Robbins, S., Organisation Theory: Structure, Design, and Application, 3/e, 1990, Prentice Hall Int., Englewood, N. J.

Scott, J. (1987) "Intercorporate Structures in Western Europe: A Comparative Historical Analysis”, In: Intercorporate Relations: The Structural Analysis of Business, Mizruchi, M., \& Schwartz, M. (Eds.), Cambridge University Press, N.Y., pp. 208-232.

Seth, A. \& Thomas, H. (1994) “Theories of the Firm in Strategy Research", In: Journal of Management Studies, Vol. 31, No. 2, March 1994, pp. 165-191

Shapiro, C. (1989) "The Theory of Business Strategy”, In: Rand Journal of Economics, Vol. 20, No. 1, pp. 125-137.

Simon, H. (1957) Administrative Behaviour. Macmillan, New York.

Thompson, G. (1991) "Networks: Introduction” In: Markets, Hierarchies \& Networks: The Coordination of Social Life, Ed. by Thompson, G. et.al, Sage Publ., London.

Thornton, P. and Brandon, N., (1995) "The Problem of Boundaries in Contemporary Research on Organisations”, In: Best Papers Proceedings Academy of Management, Ed. by D. Moore, pp. 276-280.

Tichy, N. et. al., (1979) "Social Network Analysis for Organisations", In: Academy of Management Review, 4, pp. 507-519.

Wellman, B. (1988) "Structural Analysis: From Method and Metaphor to Theory and Substance”, In: Social Structures: A Network Approach, Ed. by Wellman, B. and Berkowitz, S., Cambridge, Mass: Cambridge University Press.

White, H., (1988) "Varieties of Markets", In: Social Structures: A Network Approach, Ed. by Wellman, B. and Berkowitz, S., Cambridge, Mass: Cambridge University Press.

White, H. (1992) “Agency as Control in Formal Networks”, In: Networks and Organisations: Structure, Form, and Action, Ed. by Nohria, N. and Eccles, R., Harvard Business School Press, Boston, Massachusetts.

Williamson, Oliver (1975) Markets and Hierarchies. Analysis and Antitrust Implications. New York: The Free Press.

Williamson, Oliver (1981) “The Economics of Organisations: The Transaction Cost Approach”. American Journal of Sociology. Vol. 87 (3): 548-577.

Williamson, Oliver (1985) The Economic Institutions of Capitalism. New York: Free Press. 